\title{
Preservation of Bioactive Compounds and Quality Parameters of Watermelon Juice Enriched with L-Citrulline through Short Thermal Treatment
}

\author{
Martha P. Tarazona-Díaz, ${ }^{1}$ Ascensión Martínez-Sánchez, ${ }^{2,3}$ and Encarna Aguayo ${ }^{2,3}$ \\ ${ }^{1}$ Department of Food Engineering, Universidad Jorge Tadeo Lozano, Carrera 4, No. 22-61, Bogotá, Colombia \\ ${ }^{2}$ Postharvest and Refrigeration Group, Department of Food Engineering, Universidad Politécnica de Cartagena, \\ Paseo Alfonso XIII 48, Cartagena, 30203 Murcia, Spain \\ ${ }^{3}$ Institute of Plant Biotechnology, Universidad Politécnica de Cartagena, Plaza del Hospital s/ $n$, \\ Campus Muralla del Mar, Cartagena, 30202 Murcia, Spain
}

Correspondence should be addressed to Encarna Aguayo; encarna.aguayo@upct.es

Received 11 May 2017; Revised 13 August 2017; Accepted 12 September 2017; Published 29 October 2017

Academic Editor: Jorge Moreno

Copyright (C) 2017 Martha P. Tarazona-Díaz et al. This is an open access article distributed under the Creative Commons Attribution License, which permits unrestricted use, distribution, and reproduction in any medium, provided the original work is properly cited.

L-citrulline is a nonessential amino acid with demonstrated health benefits for humans, and watermelon is a fruit rich in this amino acid. The juice industry is developing functional beverages through the enrichment with external bioactive compounds; this kind of industry uses conventional pasteurization because of its efficiency and simplicity. In this experiment, the effects of pasteurization $\left(80^{\circ} \mathrm{C}\right.$ for $40 \mathrm{~s}$ or $\left.90 \mathrm{~s}\right)$ and storage $\left(4^{\circ} \mathrm{C}\right.$ for 30 days) on different parameters were evaluated in a watermelon juice $\left(3.68 \mathrm{~g} \mathrm{~kg}^{-1}\right.$ of natural L-citrulline) enriched with external L-citrulline $\left(12 \mathrm{~g} \mathrm{~kg}^{-1}\right)$. Enzymatic activity (peroxidase, pectin methyl esterase, and polygalacturonase) was inactivated ( 74 to $89 \%, 89$ to $90 \%$, and 11 to $15 \%$, resp.) with the pasteurization treatment, obtaining the highest degradation with the longest heating time. According to the rheology study, the juice's elasticity was mainly affected by type of heat treatment while its viscosity was more stable and affected by storage time. A reduction in bioactive compounds content, around $10-16 \%$ for lycopene and $19-20 \%$ for L-citrulline, was observed after the pasteurization treatments, with a higher decrease with increased treatment time. Storage time also induced a reduction in lycopene and L-citrulline. The shelf life was limited by sensorial parameters.

\section{Introduction}

At present, there is growing consumer interest on the benefits of foods with functional properties, as these foods have improved nutritional value, promoting better health and disease risk reduction. At this time, the food industry is promoting functional juices rich in vitamins, minerals, and antioxidants to help maintain good health. As a result, the market acceptance of watermelon juice is increasing worldwide due to its sensorial and health properties. Watermelon is very rich in bioactive compounds such as lycopene and L-citrulline, which makes it an extremely attractive product for consumers, with excellent growth prospects in the juice market $[1,2]$. Lycopene is a carotenoid of great interest due to its antioxidant capacity and its role in the reduction of coronary heart disease and some types of cancers such as prostate and kidney cancer [3]. L-citrulline is a nonessential amino acid that can be metabolized to L-arginine, an essential amino acid for humans, which produces nitric oxide (NO) [4], improving athletic performance and relieving muscle soreness [5]; it also has cardioprotective effects [6] among other properties. Thus, L-citrulline is commercially available in the form of pharmaceutical compounds or more recently as dietary supplement beverages such as juices. Watermelon juice enriched with L-citrulline can be defined as a functional food according to Goldberg [7]. A functional food is any food or food ingredient that has a positive impact on an individual's health, physical performance, or state of mind in addition to having nutritive value. Mandel et al. [1] described an increase in plasma citrulline and arginine 
after the intake of $3.3 \mathrm{~kg}$ (fresh weight) of ripe watermelon. Moreover, Tarazona-Díaz et al. [5] observed that $500 \mathrm{~mL}$ of watermelon juice with $1.17 \mathrm{~g}$ or $6 \mathrm{~g}$ of L-citrulline helped to reduce the recovery heart rate and muscle soreness after $24 \mathrm{~h}$.

Watermelon pulp contains from 1.1 to $4.7 \mathrm{~g}$ of L-citrulline $\mathrm{kg}^{-1}$ of fresh weight [2]. These variations could be due to preharvest and postharvest factors, which can affect the final concentration in juices. Therefore, watermelon juice should undergo an industrial process to guarantee its quality and safety during the shelf life of the product. One effective way of limiting microbial growth is to increase the juice's acidity by adding an acidifier in addition to other treatments such as high hydrostatic pressure pasteurization or conventional thermal treatments. Thermal treatments are still used by most of the fruit juice processing industries due to their simplicity and efficiency. Heat treatments are conventionally used to inactivate enzymes, ensure safety, and extend the shelf life of juices [8], but undesirable changes such as loss of bioactive compounds and sensory quality reduction are often induced $[8,9]$. Reducing peroxidase (POD) activity in watermelon juice is important for avoiding color deterioration, off-flavor formation, and loss of nutrients [10]. On the other hand, decreasing the pectin methyl esterase (PME) and polygalacturonase (PG) activities could limit the degradation of pectins, decreasing the losses in viscosity and cloud stability [11]. Previously, Tarazona-Díaz and Aguayo [12] described that centrifugation and pasteurization $\left(87.7^{\circ} \mathrm{C}\right.$ for $\left.20 \mathrm{~s}\right)$ of an acidified watermelon juice significantly reduced the red color, bioactive compounds (lycopene, antioxidant capacity, and total polyphenols), and sensory quality of the juice.

Hence, the creation of a noncentrifuged watermelon juice and the determination of the best timing and temperature conditions is important, as it could help maintain the attractive red color and sensorial quality, which are characteristic of watermelon juice, as well as the content of bioactive compounds, particularly lycopene and L-citrulline. In this experiment, we studied the effects of two different pasteurization treatments $\left(80^{\circ} \mathrm{C}\right.$, for $40 \mathrm{~s}$ or $\left.90 \mathrm{~s}\right)$ on shelf life under market storage conditions of a functional watermelon juice (3.68 $\mathrm{g} \mathrm{kg}^{-1}$ of natural L-citrulline) enriched with external Lcitrulline $\left(12 \mathrm{~g} \mathrm{~kg}^{-1}\right)$.

\section{Materials and Methods}

2.1. Watermelon Juice Preparation. Seedless watermelons (Citrullus lanatus cv. "Fashion") were grown in open fields with a Mediterranean climate (Águilas, Murcia, Spain) and were harvested in late July at the commercial maturity stage $\left(>9.0^{\circ}\right.$ Brix). The fruits were transported $(80 \mathrm{~km})$ in a refrigerated vehicle to the laboratory in the Technical University of Cartagena (UPCT, Murcia, Spain) and kept at $10^{\circ} \mathrm{C}$ and $90 \%$ relative humidity $(\mathrm{RH})$ in darkness until the next morning. Ten selected fruits, free from defects, with an average weight of $6.20 \pm 0.23 \mathrm{~kg}$, were washed (100 $\mathrm{mg} \mathrm{L}^{-1}$ sodium hypochlorite at $\mathrm{pH} 6.5$ for $2 \mathrm{~min}$ ) and dried. Afterwards, the pulp was separated from the skin and cut into sections $(3 \mathrm{~cm})$ and liquefied (Moulinex FruttiProBKA1, Spain), obtaining about $35 \mathrm{~L}$ of juice.
The juice, which contained $3.68 \mathrm{gL}^{-1}$ of natural Lcitrulline, was enriched with $12 \mathrm{~g} \mathrm{~L}^{-1}$ of L-citrulline (Acofarma, Barcelona, Spain). The $\mathrm{pH}$ was adjusted to $3.80 \pm$ 0.08 by adding citric acid (Panreac, Barcelona, Spain) [11]. The total volume of watermelon juice was subsequently separated into three groups as follows: (a) two pasteurization watermelon juice (PWJ) treatments at $80^{\circ} \mathrm{C}$ for $40 \mathrm{~s}$ (PWJ$40 \mathrm{~s}$ ), at $80^{\circ} \mathrm{C}$ for $90 \mathrm{~s}$ (PWJ-90 s) and cooling conducted in a thermoresistometer (Mastia, Cartagena, Spain) [13] and (b) unpasteurized watermelon juice (UPWJ) used as control treatment. This equipment was provided with software that allowed for the recording of both the pasteurization and cooling temperatures. This consisted of a stainless-steel container where the watermelon juice sample was placed, heated by means of an electric resistance, and continuously stirred with the provided stirrer. After pasteurization at the set temperature and time, the thermoresistometer was programmed to automatically cool to $10^{\circ} \mathrm{C}$, through a cold water bath $\left(1.4-2^{\circ} \mathrm{C}\right)$ that was connected to the equipment. The cooling rate was $7^{\circ} \mathrm{C} \mathrm{min}{ }^{-1}$. Finally, when the cooling temperature was stabilized, the vessel containing the pasteurized juice was removed, and amber bottles, which were previously sterilized $\left(121^{\circ} \mathrm{C}\right.$ for $\left.15 \mathrm{~min}\right)$, were rapidly filled under sterilized conditions and kept at $4^{\circ} \mathrm{C}$ for 30 days in a refrigerated incubator (Sanyo, Japan). For each pasteurization treatment, three rounds of pasteurization were performed. During the 30 days of storage time, samples were evaluated every 5 days, using three replicates per treatment (bottles of $150 \mathrm{~mL}$ ) for each sampling day. Prior to collection of the data for the present work, two preliminary experiments were performed to observe changes and to establish the experimental conditions.

2.2. Analysis of Physicochemical Attributes. The analytical parameters $\mathrm{pH}$ (Crison $2001 \mathrm{pH}$ meter, Crison Instruments SA, Barcelona, Spain) and solid soluble content (SSC) (digital refractometer, Atago Company Ltd., Tokyo, Japan) were measured as described by Tarazona-Díaz and Aguayo [12].

2.3. Color Measurements. Watermelon juice color at three equidistant points was determined using a Chroma meter (CR-300, Minolta, Ramsey, NY, USA) as described by Tarazona-Díaz and Aguayo [12]. The results are expressed as hue angle $\left({ }^{\circ} h=\tan ^{-1}\left(b^{*} / a^{*}\right)\right)$ and color index (CI $=$ $\left.\left[\left(a^{*}\right)(1000)\right] /\left[\left(L^{*}\right)\left(b^{*}\right)\right]\right)$.

\subsection{Biofunctional Compounds}

2.4.1. Lycopene Content. Lycopene content was determined according to the methodology reported by Fish et al. [14] with some modifications [2]. Results are expressed as mg lycopene $\mathrm{kg}^{-1}$ watermelon juice.

2.4.2. Citrulline Content. Citrulline analyses were carried out by HPLC-DAD-MS-APCI for the analysis of underivatized free amino acids in foods [15]. Total citrulline content was expressed as $\mathrm{g} \mathrm{kg}^{-1}$ of watermelon juice. 


\subsection{Enzymatic Activity}

2.5.1. Peroxidase (POD; EC 1.11.1.7). POD activity in watermelon juice samples $(10 \mathrm{~mL})$ was measured using the method described by Elez-Martínez et al. [16] with some modifications. POD activity was determined in the supernatant by using 96-well microplates (Greiner Bio-One, Frickenhausen, Germany) in a Tecan Infinite ${ }^{\circledR} 200$ microplate reader (Grödig, Austria) at $509 \mathrm{~nm}$ for $10 \mathrm{~min}$ at $25^{\circ} \mathrm{C}$. The reaction was started by adding $9 \mu \mathrm{L}$ of the enzymatic extract to the well containing $243 \mu \mathrm{L}$ of reaction medium described by ElezMartínez et al. [16]. The enzyme activity unit was defined as the variation of 0.001 units of absorbance per min per $\mathrm{mL}$ of protein extract. The protein concentration was calculated according to the Bradford method [17].

2.5.2. Pectin Methylesterase (PME; EC 3.1.1.11). PME activity was measured using the method described by Kimball [11] and Anthon et al. [18] with some modifications. Watermelon juice (10 mL of each sample), previously warmed to $30^{\circ} \mathrm{C}$ in a water bath (JP Selecta, Barcelona, Spain), was mixed with pectin-salt substrate at $1 \%(40 \mathrm{~mL})$ and incubated at $30^{\circ} \mathrm{C}$ and the $\mathrm{pH} 7$ was adjusted with $2 \mathrm{~N} \mathrm{NaOH}$. Consumption of $0.05 \mathrm{~N}$ of $\mathrm{NaOH}$ (98\% purity, Panreac, Spain) was recorded each minute during the reaction period of $10 \mathrm{~min}$. The PME activity was expressed in units (U) PME per $\mathrm{mL}$ of watermelon juice.

2.5.3. Polygalacturonase (PG; EC 3.2.1.15). The determination of PG was carried out in watermelon juice samples $(2.5 \mathrm{~mL})$ using the method described by Aguiló-Aguayo et al. [19] with some modifications. The pellet dissolved in $\mathrm{NaCl}$ was shaken at $200 \mathrm{rpm}$ (orbital shaker, Stuart SSL1, UK) at $4^{\circ} \mathrm{C}$ for $1 \mathrm{~h}$. PG activity unit $(\mathrm{U})$ was expressed as micromoles of galacturonic acid reducing equivalent per $\mathrm{mL}$ of watermelon juice per minute at $35^{\circ} \mathrm{C}$. As a standard, $\alpha$-D-galacturonic acid $(\geq 98 \%$ purity, Sigma, Spain) was used.

2.6. Rheological Measurements. Stability was measured as described by Ramos and Ibarz [20]. Rheological experiments were executed using an AR G2 stress-controlled rheometer (TA Instruments, New Castle, US) equipped with a $40 \mathrm{~mm}$ aluminum plate. Samples $(30 \mathrm{~mL})$ were analyzed at $15^{\circ} \mathrm{C}$. Frequency tests were performed within the linear viscoelastic region in a range of $100-0.01 \mathrm{~Hz}$. The results of the oscillatory rheological measurements were expressed in terms of the storage modulus $\left(G^{\prime}\right)$ in Pascals $(\mathrm{Pa})$, where $G^{\prime}$ measured the material's ability to store energy. Three replicates of each treatment were analyzed in duplicate.

2.7. Microbial Analyses. Samples weighing $25 \mathrm{~g}$ were homogenized for $10 \mathrm{~s}$ in $0.1 \%$ sterile buffered peptone water (AES Laboratoire, Combourg, France) (1:10 dilution). Standard enumeration methods were used to determine the microbial growth. For the enumeration of each microbial group (mesophilic, Staphylococcus aureus, enterobacteria, and yeasts and filamentous fungi), a dilution series were prepared in $9 \mathrm{~mL}$ of sterile, buffered peptone water (Scharlau
Chemie SA, Barcelona, Spain). The presence of Salmonella spp., Listeria monocytogenes, and Escherichia coli was also evaluated according to the EU legislation (Regulation EC $1441 / 2007,2007)$ [21]. The media and incubation conditions for each microbial group were previously described by Tarazona-Díaz and Aguayo [12]. Three samples (bottles of juice) of watermelon juice (UPWJ, PWJ-40 s, and PWJ-90 s) were analyzed in duplicate at day 0 and at every 5 days of storage. Microbiological counts were expressed as log colony forming units per $\mathrm{mL}$ of juice $\left(\log \mathrm{CFU} \mathrm{mL} \mathrm{m}^{-1}\right)$.

2.8. Sensorial Analyses. Evaluation of the sensorial quality of watermelon juice (color, aroma, taste, and overall acceptability) was performed in a room at $20^{\circ} \mathrm{C}$. The evaluations were performed by a panel of 15 judges (eight female and seven male; aged between 25 and 60 years) trained to recognize and score the quality attributes of watermelon juice using fresh and stored samples. Each juice was presented in a randomized order. Approximately $20 \mathrm{~mL}$ of sample juice in a clear plastic cup with a 3-digit code was given to each panel member. A nine-point hedonic scale was used: $1=$ extremely dislike, not characteristic of the product, $5=$ neither like nor dislike, limit of acceptance from the consumers' point of view, 9 = extremely like, very characteristic of the product [22]. The definition for this juice was natural product, $100 \%$ obtained from the edible part of ripe and fresh watermelons, obtained via a mechanical extraction procedure, followed by pasteurization as a preservation treatment, without added sugars, without preservatives. The color of the juice must be an intense red, with good appearance, characteristic watermelon aroma and taste, and good acceptance.

2.9. Statistical Analysis. Analysis of variance (ANOVA) was performed to compare the different pasteurization treatments and storage times at a significance level of $p \leq 0.05$ using SPSS Statistics 22 for Windows (SPSS Inc., Chicago, IL, USA). In some cases, when significant differences were observed, Tukey's HSD (Honestly Significant Difference) test was applied. In the rest of cases, the least significant differences (LSD) test at a significance level of $p \leq 0.05$ for pasteurization treatments and storage time was used, with the results shown in the figures and the table. Bilateral correlations were determined by Pearson's correlation coefficient with confidence intervals set at $95 \%$.

\section{Results and Discussion}

3.1. Analysis of Physical and Chemical Attributes. The initial $\mathrm{pH}$ of the acidified UPWJ was $3.80 \pm 0.08$. No significant differences were observed in $\mathrm{pH}$ or SSC with thermal treatment. The $\mathrm{pH}$ increased slightly with pasteurization to 3.86 and 3.89 for PWJ-40 s and PWJ-90 s, respectively. SSC had an average of $10.17 \pm 0.03^{\circ}$ Brix. However, the storage time significantly reduced the $\mathrm{pH}$ and SSC. After 30 days of storage, the $\mathrm{pH}$ was $3.68 \pm 0.01$ and SSC decreased to $10.07 \pm 0.03^{\circ}$ Brix, without differences between the thermal treatments. In other types of juices such as orange, pasteurization at $94.6^{\circ} \mathrm{C}$ for $30 \mathrm{~s}$ maintained $\mathrm{pH}$ and SSC during the 22 days of storage at $4^{\circ} \mathrm{C}$, 
TABLE 1: Effects of pasteurization treatment $\left(80^{\circ} \mathrm{C}\right.$ for $40 \mathrm{~s}$ or $\left.90 \mathrm{~s}\right)$ and storage $\left(4^{\circ} \mathrm{C}\right.$ for 30 days) on lycopene and L-citrulline content of watermelon juice enriched with L-citrulline.

\begin{tabular}{|c|c|c|c|c|c|c|}
\hline \multirow{2}{*}{$\begin{array}{l}\text { Storage time } \\
\text { (days) }\end{array}$} & \multicolumn{3}{|c|}{ Lycopene $\left(\mathrm{mg} \mathrm{kg}^{-1}\right)$} & \multicolumn{3}{|c|}{ L-citrulline $\left(\mathrm{g} \mathrm{kg}^{-1}\right)$} \\
\hline & UPWJ & PWJ-40s & PWJ-90 s & UPWJ & PWJ-40 s & PWJ-90s \\
\hline 0 & \multirow{7}{*}{$12.97 \pm 0.08^{\mathrm{A}}$} & $11.72 \pm 0.40^{\mathrm{Ba}}$ & $10.91 \pm 0.60^{\mathrm{Ca}}$ & \multirow{7}{*}{$15.68 \pm 0.05^{\mathrm{A}}$} & $12.75 \pm 0.03^{\mathrm{Ba}}$ & $12.59 \pm 0.16^{\mathrm{Ba}}$ \\
\hline 5 & & $11.70 \pm 0.02^{\mathrm{Aa}}$ & $10.95 \pm 0.15^{\mathrm{Ba}}$ & & $12.75 \pm 0.03^{\mathrm{Aa}}$ & $12.56 \pm 0.03^{\mathrm{Ba}}$ \\
\hline 10 & & $11.72 \pm 0.11^{\mathrm{Aa}}$ & $10.92 \pm 0.34^{\mathrm{Ba}}$ & & $12.74 \pm 0.03^{\mathrm{Aa}}$ & $12.54 \pm 0.05^{\mathrm{Bab}}$ \\
\hline 15 & & $11.55 \pm 0.11^{\mathrm{Aa}}$ & $10.90 \pm 0.13^{\mathrm{Ba}}$ & & $12.70 \pm 0.01^{\mathrm{Aab}}$ & $12.48 \pm 0.03^{\mathrm{Bab}}$ \\
\hline 20 & & $11.44 \pm 0.08^{\mathrm{Aa}}$ & $10.70 \pm 0.08^{\mathrm{Ba}}$ & & $12.52 \pm 0.01^{\mathrm{Aabc}}$ & $12.40 \pm 0.03^{\mathrm{Babc}}$ \\
\hline 25 & & $10.98 \pm 0.12^{\mathrm{Aab}}$ & $10.48 \pm 0.17^{\mathrm{Bab}}$ & & $12.49 \pm 0.02^{\mathrm{Abc}}$ & $12.33 \pm 0.04^{\mathrm{Bbc}}$ \\
\hline 30 & & $10.51 \pm 0.16^{\mathrm{Ab}}$ & $10.13 \pm 0.15^{\mathrm{Bb}}$ & & $12.38 \pm 0.03^{\mathrm{Ac}}$ & $12.04 \pm 0.09^{\mathrm{Bc}}$ \\
\hline
\end{tabular}

UPWJ, unpasteurized watermelon juice. PWJ-40 s, pasteurized watermelon juice for $40 \mathrm{~s}$. PWJ-90 s, pasteurized watermelon juice for $90 \mathrm{~s}$. Values correspond to measurements $(n=3) \pm$ SE. Different capital letters in the same row show significant differences between treatments. Different lower case letters in the same column show significant differences between storage times. Control samples were only evaluated to test significant differences between pasteurized treatments at 0 days.

after which the microorganisms reduced the $\mathrm{pH}$ and ${ }^{\circ} \mathrm{Brix}$ values [23]. Esteve et al. [24] reported that the decrease in $\mathrm{pH}$ in refrigerated orange juices from Spain could indicate the start of spoilage or fermentation of the sample.

3.2. Color Measurements. The color of a product is the first quality factor that the consumer takes into account and has an important influence on the acceptance of a beverage. In this experiment, color was affected by pasteurization treatments and time of storage and by the interaction between both factors. The $a / b$ ratio, which is frequently used to evaluate the redness of juices, showed a reduction without significant differences between pasteurization times (data not shown). Aguiló-Aguayo et al. [25] previously reported that watermelon juices subjected to heat treatment $\left(90^{\circ} \mathrm{C}, 60 \mathrm{~s}\right)$ exhibited an increase in a and b values, which may be due to the formation of dark compounds causing browning of juices. The effects of pasteurization and storage time on $h^{\circ}$ and color index (CI) of thermal juices are shown in Figure 1. Chroma and $h^{\circ}$ from PWJ increased the value with respect to UPWJ, but CI decreased in thermal-treated juices. The PWJ$90 \mathrm{~s}$ treatment resulted in a juice with less red color (increased ${ }^{\circ} h$ and decreased CI) than PWJ-40s. The pasteurization time, $90 \mathrm{~s}$ versus $40 \mathrm{~s}$, could induce a higher oxidation of thermolabile pigments that are responsible for the red color such as lycopene (Table 1). S. Srivastava and A. K. Srivastava [26] reported that under heat treatment lycopene is degraded via isomerization and oxidation.

In both thermal treatments, a red-orange color was observed with storage. The highest values in Chroma and $h^{\circ}$ were detected at 10 days of storage in both pasteurization treatments. These changes in color were probably associated with the loss of stability due to the residual enzymatic activity found in watermelon juices (Figure 2).

\subsection{Biofunctional Compounds}

3.3.1. Lycopene Content. The initial lycopene content in untreated watermelon juice was $12.97 \pm 0.08 \mathrm{mg} \mathrm{kg}^{-1}$. After pasteurization, the content was reduced by around $10 \%$ for PWJ-40s and around 16\% for PWJ-90s (Table 1). During storage, no significant differences were observed between the lycopene contents at day 0 after the treatments and at 25 days of storage, with the samples pasteurized for $40 \mathrm{~s}$ maintaining the highest content (Table 1). In this study, lycopene content was more affected by pasteurization conditions $\left(80^{\circ} \mathrm{C}, 40 \mathrm{~s}\right.$ versus $90 \mathrm{~s}$ ) than by storage conditions ( $4^{\circ} \mathrm{C}$ for 30 days), although significant losses at the end of storage were also observed. At 30 days of storage, the lycopene losses were around $10 \%$ for PWJ-40 s and $7 \%$ for PWJ-90 s. Similar results were reported for watermelon juice, which showed higher losses after thermal treatment $\left(88^{\circ} \mathrm{C}\right.$ for $\left.20 \mathrm{~s}\right)$ than during the 30 days of storage time [12]. Additionally, a previous study detected a loss of about $40 \%$ in the lycopene content after conventional sterilization of tomato puree [27]. However, Knockaert et al. [28] only measured a significant decrease (20-30\%) in the lycopene content of tomato puree after thermal sterilization $\left(117^{\circ} \mathrm{C}\right.$ for $1.5 \mathrm{~min}$ or $\left.3 \mathrm{~min}\right)$, while no significant differences between tomato puree treated at $90^{\circ} \mathrm{C}$ for $10 \mathrm{mins}$ and $60^{\circ} \mathrm{C}$ for $1 \mathrm{~min}$ and untreated samples were observed.

The degradation of lycopene is influenced by factors such as oxygen, light, reaction medium, temperature, physical state, and environmental conditions. Lee and Chen [29] studied the stability of lycopene by heating standard lycopene at $50^{\circ} \mathrm{C}, 100^{\circ} \mathrm{C}$, and $150^{\circ} \mathrm{C}$. For $50^{\circ} \mathrm{C}$, there was no significant change in all-trans-lycopene found within the first 12 hours. For $100^{\circ} \mathrm{C}$ the levels of all-trans-lycopene decreased by $78 \%$ after 120 minutes of heating. The mono-cis forms of lycopene showed a decreasing trend in concentration, and for $150^{\circ} \mathrm{C}$ not all-trans lycopene was detected after $10 \mathrm{~min}$. The levels of all the mono-cis forms of lycopene showed the same trend. These authors concluded that due to the increasing temperature and heating time, degradation dominated over isomerization. Moreover, Maillard reactions and Strecker degradation products were detected in the thermal treatment $\left(74^{\circ} \mathrm{C}\right.$ for $\left.45 \mathrm{~s}\right)$ of watermelon juice [30]. Lycopene was positively correlated with Chroma $\left(0.540^{* *}\right)$ and PG $\left(0.900^{*}\right)$, while showing a negative correlation with $h^{\circ}\left(-0.811^{* *}\right)$, CI $\left(-0.704^{* *}\right)$, and POD $\left(-0.986^{* *}\right)$. These results can help the beverage industry to understand how to work with 

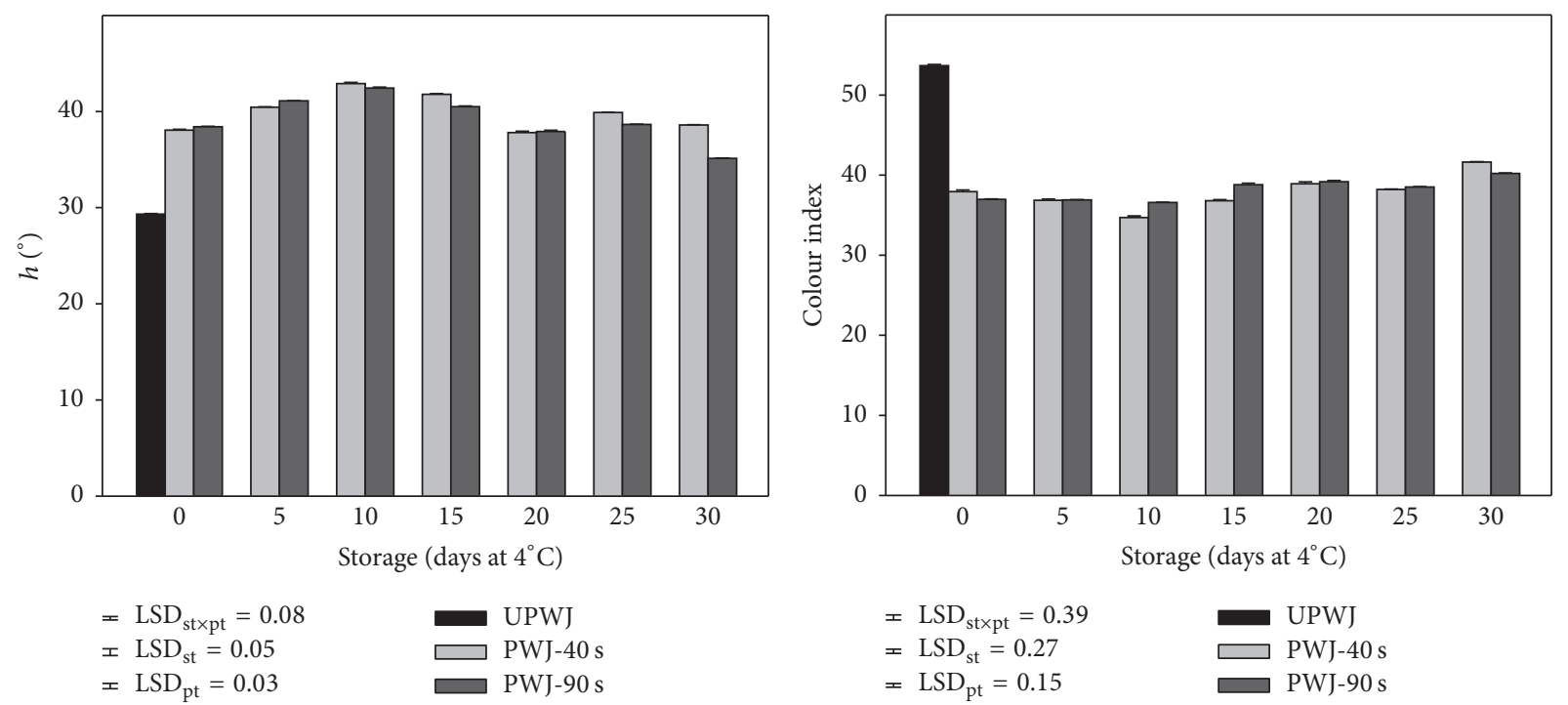

FIGURE 1: Effect of pasteurization treatment $\left(80^{\circ} \mathrm{C}\right.$ for $40 \mathrm{~s}$ or $\left.90 \mathrm{~s}\right)$ and storage $\left(4^{\circ} \mathrm{C}\right.$ for 30 days) on hue $\left(h^{\circ}\right)$ and color index (CI) of watermelon juice enriched with L-citrulline. LSD values are shown for interaction and both factors. st, storage time; pt, pasteurized treatment. UPWJ, unpasteurized watermelon juice. PWJ-40 s, pasteurized watermelon juice for $40 \mathrm{~s}$. PWJ-90 s, pasteurized watermelon juice for $90 \mathrm{~s}$.

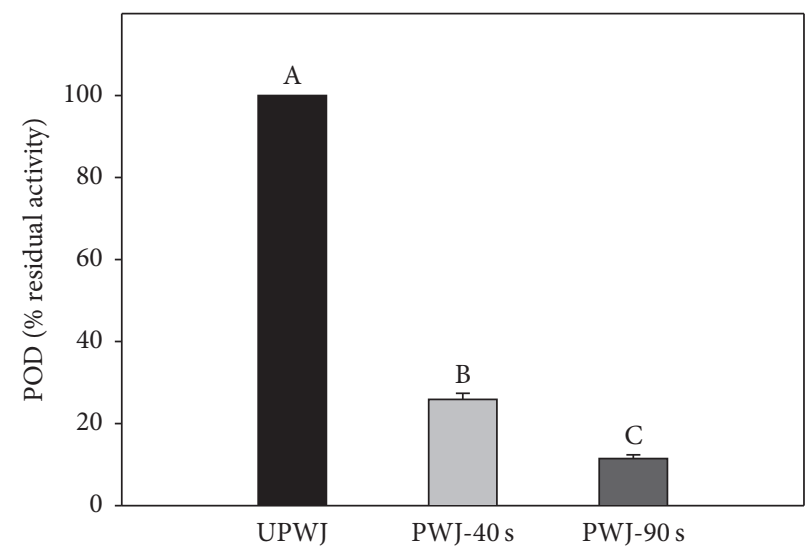

(a)

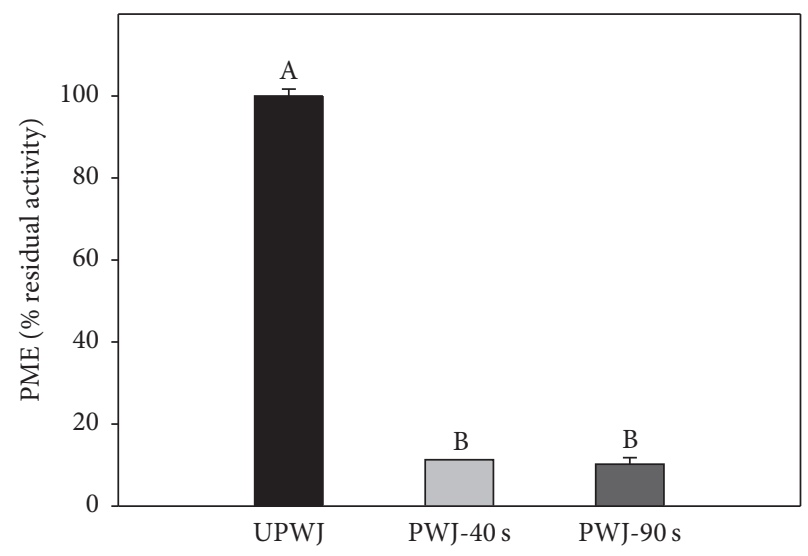

(b)

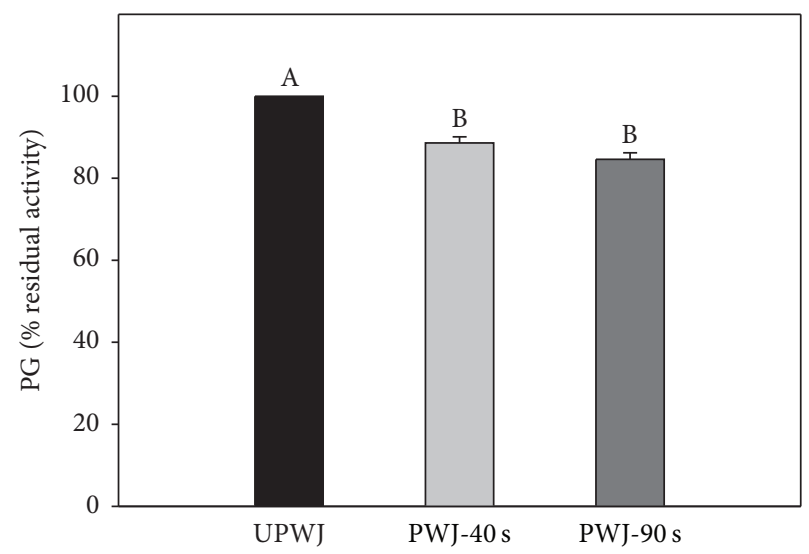

(c)

FIGURE 2: Effect of pasteurization treatment $\left(80^{\circ} \mathrm{C}\right.$ for $40 \mathrm{~s}$ or $\left.90 \mathrm{~s}\right)$ with respect to unpasteurized juice (UPWJ) at day 0 on enzymatic activity (POD, PME, and PG) of watermelon juice enriched with L-citrulline. Mean values denoted with the same letter do not significantly differ statistically, $p \leq 0.05$. UPWJ, unpasteurized watermelon juice. PWJ-40 s, pasteurized watermelon juice for $40 \mathrm{~s}$. PWJ-90 s, pasteurized watermelon juice for $90 \mathrm{~s}$. 
these parameters so that the lycopene contents of the juices are better retained. On the other hand, the presence and stability of other antioxidants such as polyphenols or thermal inactivation oxidizing enzymes (such as POD) could promote the lycopene stability [31].

3.3.2. Citrulline Content. The natural L-citrulline content in watermelon juice was of $3.68 \mathrm{~g} \mathrm{~kg}^{-1}$. It was supplemented with $12 \mathrm{~g} \mathrm{~kg}^{-1}$ previous to heat treatments, so the initial L-citrulline content in enriched watermelon juice was $15.68 \mathrm{~g} \mathrm{~kg}^{-1}$. Amino acids are highly important components of the daily diet, even at relatively low levels. In addition, as citrulline supplementation increases plasma concentration of both arginine and citrulline, the enriched watermelon juice could be considered a functional beverage, as it enhances sports nutrition in humans [32] and can be used to prevent arginine and nitric oxide deficiencies under various physiological and pathological conditions [33].

After heat treatments, L-citrulline was degraded around 19\% (for PWJ-40s) and 20\% (for PWJ-90 s) without significant differences between heat treatments (Table 1). Lcitrulline content showed significant reduction at 30 days of storage (3\% loss in PWJ-40 s and 4\% loss in PWJ-90 s). As with lycopene, the heat treatment affected the L-citrulline content more than the storage conditions. These results could be related to the thermal treatment that modified the structure of amino acids. Sereewatthanawut et al. [34] have said that, with increasing temperature, some amino acids are degraded to form low molecular weight carboxylic acids such as formic, acetic, and propionic acids, resulting in a reduction of the total amino acid concentration. On the other hand, in fermented orange juice, the amino acid profile, including citrulline, was not modified by pasteurization $\left(85^{\circ} \mathrm{C}\right.$ for $30 \mathrm{~s}$ ); however, the fermentation time (9 days) significantly increased the total amino acid content [35].

3.4. Enzymatic Activity. Most of the undesirable changes in the characteristic red color, viscosity, and taste of watermelon juice are catalyzed by enzymes such as peroxidase (POD), pectin methylesterase (PME), and polygalacturonase (PG). These enzymes were analyzed at day 0.

3.4.1. POD Activity. POD activity was reduced after the application of heat treatments and was dependent on the duration of the treatment. The residual POD activity was around $26 \%$ in PWJ-40s samples and $12 \%$ in PWJ-90 s samples (Figure 2(a)). Similarly, Aguiló-Aguayo et al. [36] described a similar residual POD activity after the application of thermal treatments $\left(90^{\circ} \mathrm{C}\right.$ for $40 \mathrm{~s}$ or $\left.60 \mathrm{~s}\right)$. It was rapidly reduced in the first week of storage and remained constant until day 30. POD showed a positive correlation with $h^{\circ}$ $\left(0.955^{* *}\right)$ and a negative correlation with Chroma $\left(-0.967^{* *}\right)$, CI $\left(-0.848^{*}\right)$, and lycopene $\left(-0.986^{* *}\right)$. Therefore, the inactivation of this enzyme is very important for the maintenance of the characteristic red color of watermelon juice and its lycopene content.

3.4.2. PME Activity. Heat treatments reduced the PME activity, without significant differences between both treatments.
PWJ-40 s samples showed a residual PME activity of around $11 \%$ and PWJ-90 s of around $10 \%$ (Figure 2(b)). These values were lower than those obtained by Aguiló-Aguayo et al. [36] in watermelon juice that had been thermally treated at $90^{\circ} \mathrm{C}$ for $60 \mathrm{~s}$ or $30 \mathrm{~s}$, which obtained $25 \%$ and $38 \%$ of PME activity, respectively. Other results in clementine tangerine juice, after pasteurization at $74^{\circ} \mathrm{C}$ for $10 \mathrm{~s}$, reduced the initial value of PME activity to 7\% [37]. Changes in the percentage of inactivation could be due to the differences in plant material [18]. In addition to these results, previous authors observed that a conformational change of the enzyme could explain the high percentage of inactivation reached with mild temperatures [25]. PME is an enzyme that is known to participate in vegetable softening processes and the catalysis of the hydrolysis of methylester groups of cell wall pectin. From an industrial point of view, a juice is commercially stable when the residual enzymatic activity remains below 10\% [19]. According to our results, both pasteurized treatments could be considered commercially stable.

3.4.3. PG Activity. After thermal treatment, the residual PG activity was around $89 \%$ in PWJ-40 s and around $85 \%$ in PWJ-90 s samples, being the most thermoresistant enzyme analyzed in our study (Figure 2(c)). These values were lower than those obtained by Aguiló-Aguayo et al. [36] in watermelon juice at $90^{\circ} \mathrm{C}$ for $60 \mathrm{~s}$ or $30 \mathrm{~s}$. This author did not observe significant differences between thermally treated and nontreated juices. The incomplete reduction of PME and PG could explain the loss of stability in watermelon juice depending on the duration of the heat treatment [25]. A previous research stated that the PG present in whole tomato occurs in two forms: one stable in heat and another that is thermolabile, and therefore, the low inactivation of the PG could be attributed to the resistance of the heat-stable form of PG [19]. Therefore, the high residual PG activity obtained in our study could be due to the presence of the heat-stable PG isoform.

3.5. Rheological Features. The rheology of fruit juices is very useful in quality control and sensory evaluation and for predicting storage stability. For all the treatments, the storage modulus $\left(G^{\prime}\right)$ was always higher than the loss modulus $\left(G^{\prime \prime}\right)$ in the oscillatory frequency $(\omega)$ range evaluated (Figure 3 ). This indicates that the elastic properties of watermelon juice are dominant, rather than the viscous ones. The magnitudes of both increased with frequency. However, the dependence of $G^{\prime \prime}$ on the oscillatory frequency was greater than for $G^{\prime}$, especially at high frequencies. Moreover, the differences between $G^{\prime}$ and $G^{\prime \prime}$ decreased with the storage time, and an intersection between both curves was observed depending on treatment and day of storage. The tangent of phase angle $(\delta)$ showed the lower capacity of UPWJ to maintain integrity rather than PWJ, as well as the time of storage being affected in PWJ-90 s before PWJ-40 s (Figure 3).

At day $0, G^{\prime}$ and $G^{\prime \prime}$ increased with an increase in the oscillatory frequency of up to $80 \mathrm{~Hz}$, except in control samples, where $G^{\prime}$ started to decrease at $40 \mathrm{~Hz}$ and was crossed over with $G^{\prime \prime}$ at $19.95 \mathrm{~Hz}$ as shown by the tangent $(\delta)$ (Figure 3 ). The dynamic viscosity of the watermelon 


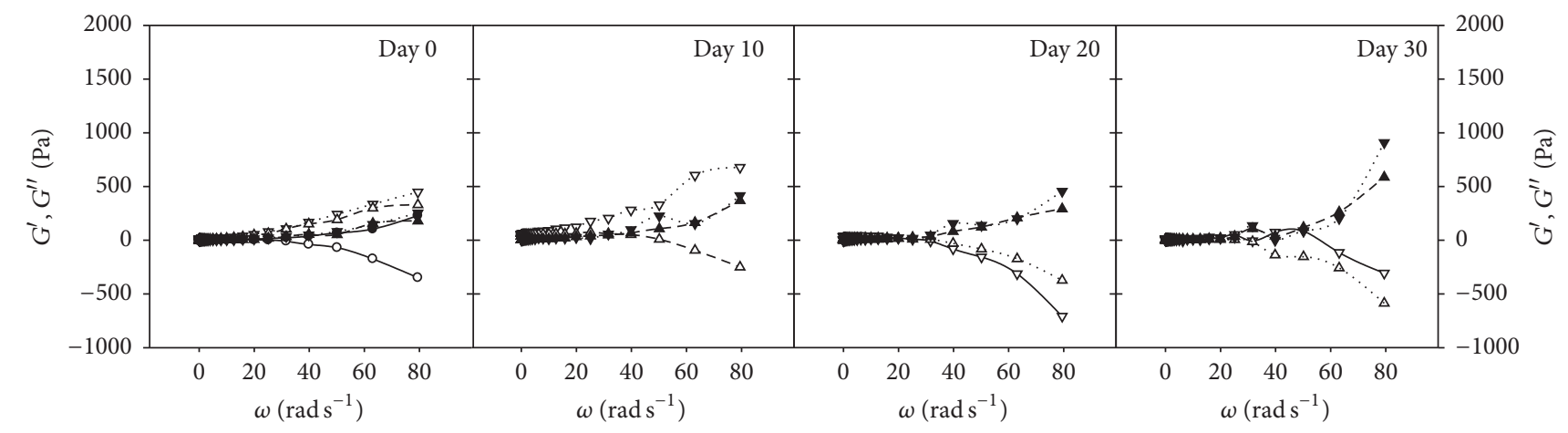

$\multimap G^{\prime}$ UPWJ

$\cdots \nabla \cdot G^{\prime}$ PWJ-40s

$-\Delta-G^{\prime}$ PWJ-90s

$\rightarrow G^{\prime \prime}$ UPWJ

$\therefore \cdot G^{\prime \prime} \mathrm{PWJ}-40 \mathrm{~s}$

- - $G^{\prime \prime}$ PWJ-90s

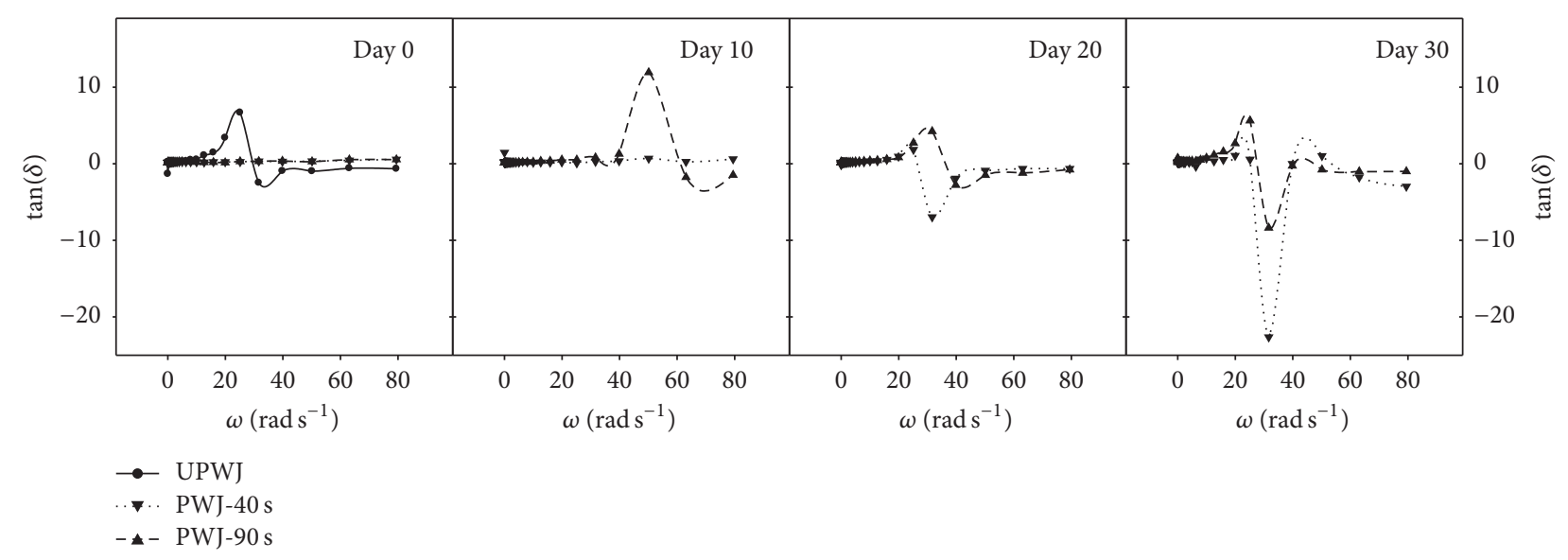

FIgURE 3: Effect of pasteurization treatments $\left(80^{\circ} \mathrm{C}\right.$ for $40 \mathrm{~s}$ or $\left.90 \mathrm{~s}\right)$ during storage at $4^{\circ} \mathrm{C}$ for 30 days on viscoelastic behaviour and loss tangent of watermelon juice enriched with L-citrulline. UPWJ, unpasteurized watermelon juice. PWJ-40 s, pasteurized watermelon juice for $40 \mathrm{~s}$. PWJ-90 s, pasteurized watermelon juice for $90 \mathrm{~s}$.

juice after thermal treatment was probably similar due to the nonsignificant differences in PME and PG residual activity in the different pasteurized juices at day 0 . Similar results were previously described in watermelon juices treated with thermal, ultraviolet- $\mathrm{C}$, and high pressure treatments at the same temperature $\left(60^{\circ} \mathrm{C}\right)$ where a correlation between PME activity and dynamic viscosity has been described [38]. In agreement with our results, Aguiló-Aguayo et al. [36] did not observe a significant change in viscosity at day 0 between treatments, detecting a lower viscosity during the storage in samples pasteurized for $30 \mathrm{~s}$ with respect to $60 \mathrm{~s}$, maintaining the highest viscosity values during the storage period. In previous studies, changes in color and viscosity of tomato juice were assigned to the activity of the enzymes POD, PME, and PG [19]. In our study, at 10 days of storage, an intersection point at $31.62 \mathrm{~Hz}$ was observed in the PWJ-90 s treatment, while at 20 days this occurred at $19.95 \mathrm{~Hz}$ for both treatments. Also, a similar point was detected at 30 days for PWJ-40 s and at $12.59 \mathrm{~Hz}$ for PWJ-90 s. These differences represent a greater degree of gel strength in PWJ-40 s as compared to PWJ$90 \mathrm{~s}$ and the changes in rheological characteristics showed by tangent $(\delta)$ could be due to changes in the concentration of pulp in suspension or a break in the microstructure of watermelon juice. These results show that pasteurization for $40 \mathrm{~s}$ provided more stability than at $90 \mathrm{~s}$, with the elastic behaviour principally affected by heat treatment and then by storage time, while viscosity was more stable and affected by storage time at higher frequencies.

3.6. Microbiological Analysis. In the present study, mesophilic aerobic bacteria, enterobacteria, yeast and filamentous fungi, Staphylococcus aureus, E. coli, Salmonella spp., and Listeria monocytogenes were analyzed. Pathogenic bacteria were not detected in any pasteurized watermelon juice. Likewise, UPWJ samples showed a $S$. aureus count close to $2 \log \mathrm{CFU} \mathrm{mL} \mathrm{L}^{-1}$, but after heat treatment $S$. aureus was not detected. Microbial counts for mesophilic aerobic bacteria, enterobacteria and yeast and filamentous fungi are shown in Figures 4(a) $-4(\mathrm{c})$.

After heat treatments, the mesophilic aerobic bacteria counts were reduced between 1.2 and 1.4 logarithmic cycles (Figure 4(a)), while an enterobacteria reduction of 


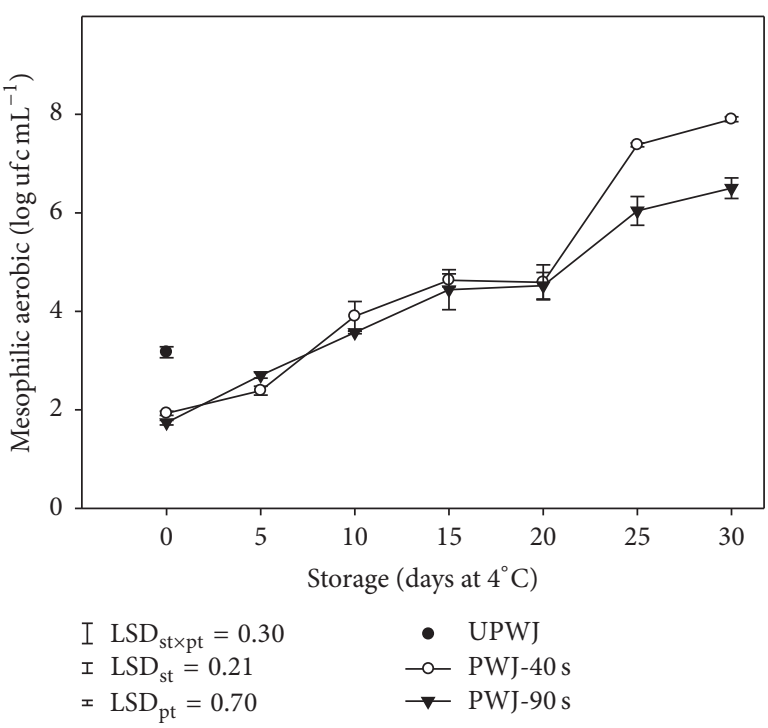

(a)

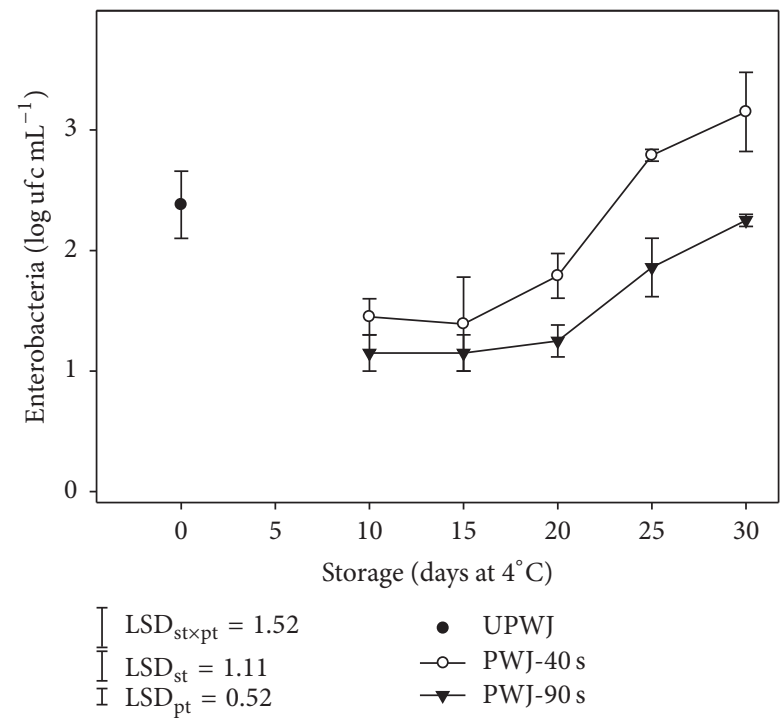

(b)

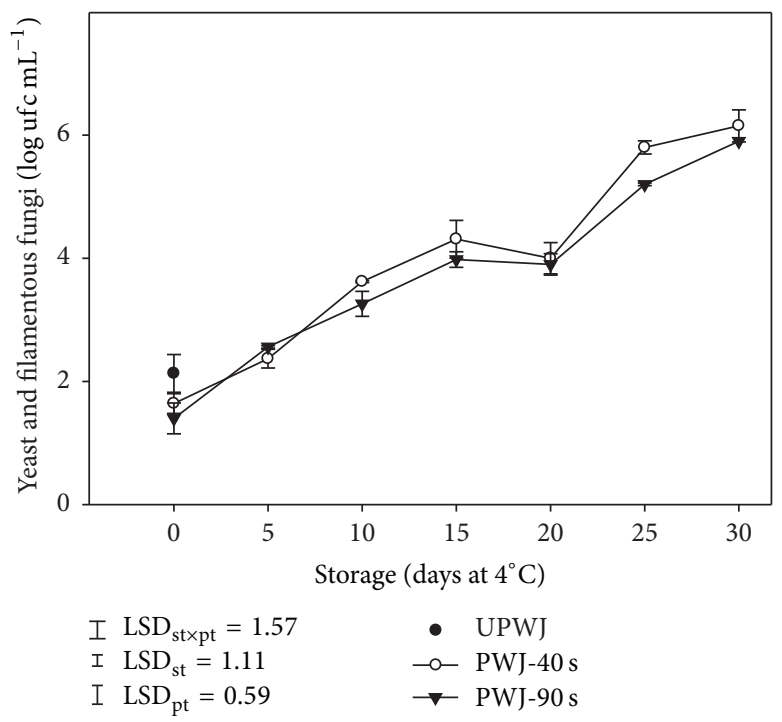

(c)

FIgURE 4: Effect of pasteurization $\left(80^{\circ} \mathrm{C}\right.$ for $40 \mathrm{~s}$ or $\left.90 \mathrm{~s}\right)$ and storage $\left(4^{\circ} \mathrm{C}\right.$ for 30 days) on microbial counts $\left(\log \mathrm{CFU} \mathrm{mL}^{-1}\right)$ of watermelon juice enriched with L-citrulline. LSD values are shown for interaction and both factors. st, storage time; pt, pasteurized treatment. UPWJ, unpasteurized watermelon juice. PWJ-40 s, pasteurized watermelon juice for $40 \mathrm{~s}$. PWJ- $90 \mathrm{~s}$, pasteurized watermelon juice for $90 \mathrm{~s}$. Enterobacteria counts remained under the detection limit $\left(<1 \log \mathrm{cfu} \mathrm{g}^{-1}\right)$ in pasteurized juices during the first 5 days of storage.

$1.3 \log \mathrm{CFU} \mathrm{mL} \mathrm{m}^{-1}$ was obtained (Figure 4(b)); it remained under $1 \log \mathrm{cfu} \mathrm{g}^{-1}$ for the thermal samples during the first 5 days of storage. Lastly, within filamentous fungi and yeasts, a reduction of 0.5 to 0.7 logarithmic cycles was obtained, depending on pasteurization time (Figure $4(\mathrm{c})$ ). The storage time showed a clear increase in the growth of mesophilic aerobic bacteria, enterobacteria, and filamentous fungi and yeast observed in the PWJ, yielding a higher growth of mesophilic bacteria and enterobacteria in PWJ-40 s juice as compared to PWJ-90s juice. At 30 days of storage at $4^{\circ} \mathrm{C}$, there was no detection of pathogenic growth and the microbial quality was tolerable in all of the thermal treatments. Therefore, the shelf life according to the microbial acceptability could reach
30 days for both types of heat treatments. These microbial counts were higher than previously detected in watermelon juice acidified and pasteurized at $87.7^{\circ} \mathrm{C}$ for $20 \mathrm{~s}$ [12].

3.7. Sensory Evaluation. The overall quality of the PWJ was significantly lower than that of the UPWJ (Figure 5). In addition, a significant reduction with the time of pasteurization and storage was detected, but there was no interaction between these factors. Mainly, taste and aroma followed by color were the parameters that were more affected by heat treatment time (data not shown). After 15 days of storage, PWJ-90 s was close to the limit of acceptability due to the low score in overall quality (Figure 5). In line with these 


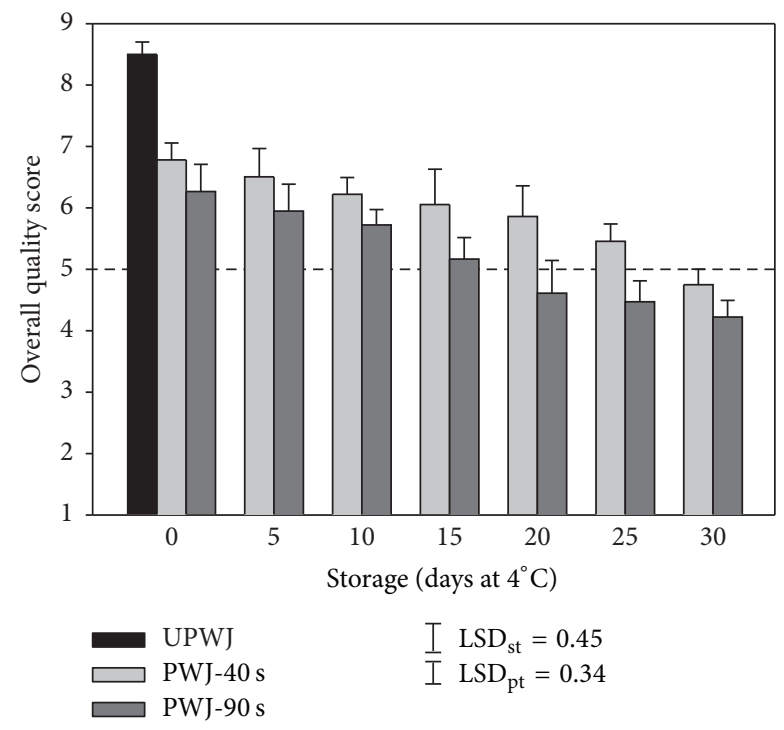

Figure 5: Effect of pasteurization $\left(80^{\circ} \mathrm{C}\right.$ for $40 \mathrm{~s}$ or $\left.90 \mathrm{~s}\right)$ and storage ( $4^{\circ} \mathrm{C}$ for 30 days) on overall quality of watermelon juice enriched with L-citrulline. Data were based on a hedonic scale where 1 is extremely dislike, 5 is limit of consumption, and 9 is extremely like. LSD values are shown for storage time (st) and pasteurized treatment (pt). UPWJ, unpasteurized watermelon juice. PWJ-40 s, pasteurized watermelon juice for $40 \mathrm{~s}$. PWJ-90 s, pasteurized watermelon juice for $90 \mathrm{~s}$.

results, the best color (determined by CIElab and sensorial analyses) and overall quality rating corresponded to PWJ$40 \mathrm{~s}$, which also had the lowest lycopene degradation rates. The overall quality at day 25 of PWJ-40 s samples was scored close to the limit of acceptability but suffered a decrease in quality at day 30 , resulting in a shelf life of one month. The lowest scores in sensorial parameters were taste followed by aroma. The reduction in sensorial quality parameters has been previously described by Aguiló-Aguayo et al. [36], who observed reductions in taste compounds when watermelon juice was thermally treated $\left(90^{\circ} \mathrm{C}, 60 \mathrm{~s}\right)$ and stored for up to 56 days at $4^{\circ} \mathrm{C}$.

\section{Conclusions}

The implementation of a pasteurization treatment is necessary in order to obtain a safe watermelon juice, but this treatment needs to be balanced with a proper treatment time to maintain functional and sensory parameters, which are easily thermodegraded. The main parameter that limits the shelf life was the sensorial quality. Thus, watermelon juice pasteurized at $80^{\circ} \mathrm{C}$ for $40 \mathrm{~s}$ (PWJ-40 s) had a shelf life that was less than 30 days and when the pasteurization was for $90 \mathrm{~s}$ (PWJ-90 s), it was less than 20 days. The use of a short thermal treatment, $80^{\circ} \mathrm{C}$ for $40 \mathrm{~s}$, incurred lycopene losses of $10 \%$ and $19 \%$ of L-citrulline after the pasteurization treatment. Storage time also induced a slight but significant reduction in both bioactive compounds. Polygalacturonase was the most thermoresistant enzyme. Knowing the quality degradation due to the pasteurization and storage period, it would be possible to establish the type of market for a functional watermelon juice and the quantity of enrichment if necessary.

\section{Conflicts of Interest}

The authors declare that there are no conflicts of interest regarding the publication of this paper.

\section{References}

[1] H. Mandel, N. Levy, S. Izkovitch, and S. H. Korman, "Elevated plasma citrulline and arginine due to consumption of Citrullus vulgaris (watermelon)," Journal of Inherited Metabolic Disease, vol. 28, no. 4, pp. 467-472, 2005.

[2] M. P. Tarazona-Díaz, J. Viegas, M. Moldao-Martins, and E. Aguayo, "Bioactive compounds from flesh and by-product of fresh-cut watermelon cultivars," Journal of the Science of Food and Agriculture, vol. 91, no. 5, pp. 805-812, 2011.

[3] A. J. Edwards, B. T. Vinyard, E. R. Wiley et al., "Consumption of watermelon juice increases plasma concentrations of lycopene and $\beta$-carotene in humans," Journal of Nutrition, vol. 133, no. 4, pp. 1043-1050, 2003.

[4] J. K. Collins, G. Wu, P. Perkins-Veazie et al., "Watermelon consumption increases plasma arginine concentrations in adults," Nutrition Journal, vol. 23, no. 3, pp. 261-266, 2007.

[5] M. P. Tarazona-Díaz, F. Alacid, M. Carrasco, I. Martínez, and E. Aguayo, "Watermelon juice: potential functional drink for sore muscle relief in Athletes," Journal of Agricultural and Food Chemistry, vol. 61, no. 31, pp. 7522-7528, 2013.

[6] Y. Ikeda, L. H. Young, R. Scalia, and A. M. Lefer, "Cardioprotective effects of citrulline in ischemia/reperfusion injury via a non-nitric oxide-mediated mechanism," Methods and Findings in Experimental and Clinical Pharmacology, vol. 22, no. 7, pp. 563-571, 2000.

[7] I. Goldberg, Functional Foods, Chapman and Hall Press, New York, NY, USA, 1994.

[8] R. J. Braddock, Handbook of Citrus By-Products and Processing Technology, Wiley, New York, NY, USA, 1999.

[9] E. Aguayo, A. Martínez-Sánchez, A. Silveira, and M. Tarazona, "Effects of pasteurization and storage time on watermelon juice quality enriched with L-citrulline," Acta Horticulturae, no. 1151, pp. 267-272, 2017.

[10] Y. Liu, X. Hu, X. Zhao, and H. Song, "Combined effect of high pressure carbon dioxide and mild heat treatment on overall quality parameters of watermelon juice," Innovative Food Science and Emerging Technologies, vol. 13, no. 1, pp. 112-119, 2012.

[11] D. A. Kimball, Quality Control and Technology, V. N. Reinhold, Ed., 1991.

[12] M. P. Tarazona-Díaz and E. Aguayo, "Influence of acidification, pasteurization, centrifugation and storage time and temperature on watermelon juice quality," Journal of the Science of Food and Agriculture, vol. 93, no. 15, pp. 3863-3869, 2013.

[13] R. Conesa, S. Andreu, P. S. Fernández, A. Esnoz, and A. Palop, "Nonisothermal heat resistance determinations with the thermoresistometer Mastia," Journal of Applied Microbiology, vol. 107, no. 2, pp. 506-513, 2009.

[14] W. W. Fish, P. Perkins-Veazie, and J. K. Collins, "A quantitative assay for lycopene that utilizes reduced volumes of organic solvents," Journal of Food Composition and Analysis, vol. 15, no. 3, pp. 309-317, 2002. 
[15] S. Özcan and H. Z. Şenyuva, "Improved and simplified liquid chromatography/atmospheric pressure chemical ionization mass spectrometry method for the analysis of underivatized free amino acids in various foods," Journal of Chromatography A, vol. 1135, no. 2, pp. 179-185, 2006.

[16] P. Elez-Martínez, R. C. Soliva-Fortuny, and O. Martín-Belloso, "Comparative study on shelf life of orange juice processed by high intensity pulsed electric fields or heat treatment," European Food Research and Technology, vol. 222, no. 3-4, pp. 321-329, 2006.

[17] M. M. Bradford, "A rapid and sensitive method for the quantitation of microgram quantities of protein utilizing the principle of protein dye binding," Analytical Biochemistry, vol. 72, no. 1-2, pp. 248-254, 1976.

[18] G. E. Anthon, Y. Sekine, N. Watanabe, and D. M. Barrett, "Thermal inactivation of pectin methylesterase, polygalacturonase, and peroxidase in tomato juice," Journal of Agricultural and Food Chemistry, vol. 50, no. 21, pp. 6153-6159, 2002.

[19] I. Aguiló-Aguayo, R. Soliva-Fortuny, and O. Martín-Belloso, "Comparative study on color, viscosity and related enzymes of tomato juice treated by high-intensity pulsed electric fields or heat," European Food Research and Technology, vol. 227, no. 2, pp. 599-606, 2008.

[20] A. M. Ramos and A. Ibarz, "Comportamiento viscoelástico de pulpa de membrillo en función de la concentración de sólidos solubles," Ciência e Tecnologia de Alimentos, vol. 26, no. 1, pp. 214-219, 2006.

[21] Regulation EC 1441/2007, "Commission regulation on microbiological criteria for foodstuffs," Official Journal of the European Union, vol. L322, pp. 12-29, 2007.

[22] D. R. Peryam and P. J. Pilgrim, "Hedonic scale method for measuring food preferences," Food Technology, vol. 11, no. 9, pp. 9-14, 1957.

[23] H. W. Yeom, C. B. Streaker, Q. Howard Zhang, and D. B. Min, "Effects of pulsed electric fields on the quality of orange juice and comparison with heat pasteurization," Journal of Agricultural and Food Chemistry, vol. 48, no. 10, pp. 4597-4605, 2000.

[24] M. J. Esteve, A. Frígola, C. Rodrigo, and D. Rodrigo, "Effect of storage period under variable conditions on the chemical and physical composition and colour of Spanish refrigerated orange juices," Food and Chemical Toxicology, vol. 43, no. 9, pp. 14131422, 2005.

[25] I. Aguiló-Aguayo, R. Soliva-Fortuny, and O. Martín-Belloso, "Avoiding non-enzymatic browning by high-intensity pulsed electric fields in strawberry, tomato and watermelon juices," Journal of Food Engineering, vol. 92, no. 1, pp. 37-43, 2009.

[26] S. Srivastava and A. K. Srivastava, "Lycopene; chemistry, biosynthesis, metabolism and degradation under various abiotic parameters," Journal of Food Science and Technology, vol. 52, no. 1, pp. 41-53, 2015.

[27] B. Krebbers, A. M. Matser, S. W. Hoogerwerf, R. Moezelaar, M. M. M. Tomassen, and R. W. van den Berg, "Combined highpressure and thermal treatments for processing of tomato puree: evaluation of microbial inactivation and quality parameters," Innovative Food Science and Emerging Technologies, vol. 4, no. 4, pp. 377-385, 2003.

[28] G. Knockaert, S. K. Pulissery, I. Colle, S. Van Buggenhout, M. Hendrickx, and A. V. Loey, "Lycopene degradation, isomerization and in vitro bioaccessibility in high pressure homogenized tomato puree containing oil: effect of additional thermal and high pressure processing," Food Chemistry, vol. 135, no. 3, pp. 1290-1297, 2012.

[29] M. T. Lee and B. H. Chen, "Stability of lycopene during heating and illumination in a model system," Food Chemistry, vol. 78, no. 4, pp. 425-432, 2002.

[30] K. Aganovic, T. Grauwet, C. Siemer et al., "Headspace fingerprinting and sensory evaluation to discriminate between traditional and alternative pasteurization of watermelon juice," European Food Research and Technology, vol. 242, no. 5, pp. 787803, 2016.

[31] G. R. Takeoka, L. Dao, S. Flessa et al., "Processing effects on lycopene content and antioxidant activity of tomatoes," Journal of Agricultural and Food Chemistry, vol. 49, no. 8, pp. 3713-3717, 2001.

[32] A. Martínez-Sánchez, D. J. Ramos-Campo, B. FernándezLobato, J. A. Rubio-Arias, F. Alacid, and E. Aguayo, "Biochemical, physiological, and performance response of a functional watermelon juice enriched in L-citrulline during a halfmarathon race," Food \& Nutrition Research, vol. 61, no. 1, p. 1330098, 2017.

[33] G. Wu, F. W. Bazer, T. A. Davis et al., "Arginine metabolism and nutrition in growth, health and disease," Amino Acids, vol. 37, no. 1, pp. 153-168, 2009.

[34] I. Sereewatthanawut, S. Prapintip, K. Watchiraruji, M. Goto, M. Sasaki, and A. Shotipruk, "Extraction of protein and amino acids from deoiled rice bran by subcritical water hydrolysis," Bioresource Technology, vol. 99, no. 3, pp. 555-561, 2008.

[35] I. Cerrillo, M. S. Fernández-Pachón, J. Collado-González et al., "Effect of fermentation and subsequent pasteurization processes on amino acids composition of orange juice," Plant Foods for Human Nutrition, vol. 70, no. 2, pp. 153-159, 2015.

[36] I. Aguiló-Aguayo, R. Soliva-Fortuny, and O. Martín-Belloso, "Color and viscosity of watermelon juice treated by highintensity pulsed electric fields or heat," Innovative Food Science and Emerging Technologies, vol. 11, no. 2, pp. 299-305, 2010.

[37] J. V. Carbonell, P. Contreras, L. Carbonell, and J. L. Navarro, "Pectin methylesterase activity in juices from mandarins, oranges and hybrids," European Food Research and Technology, vol. 222, no. 1-2, pp. 83-87, 2006.

[38] C. Zhang, B. Trierweiler, W. Li et al., "Comparison of thermal, ultraviolet-c, and high pressure treatments on quality parameters of watermelon juice," Food Chemistry, vol. 126, no. 1, pp. 254-260, 2011. 

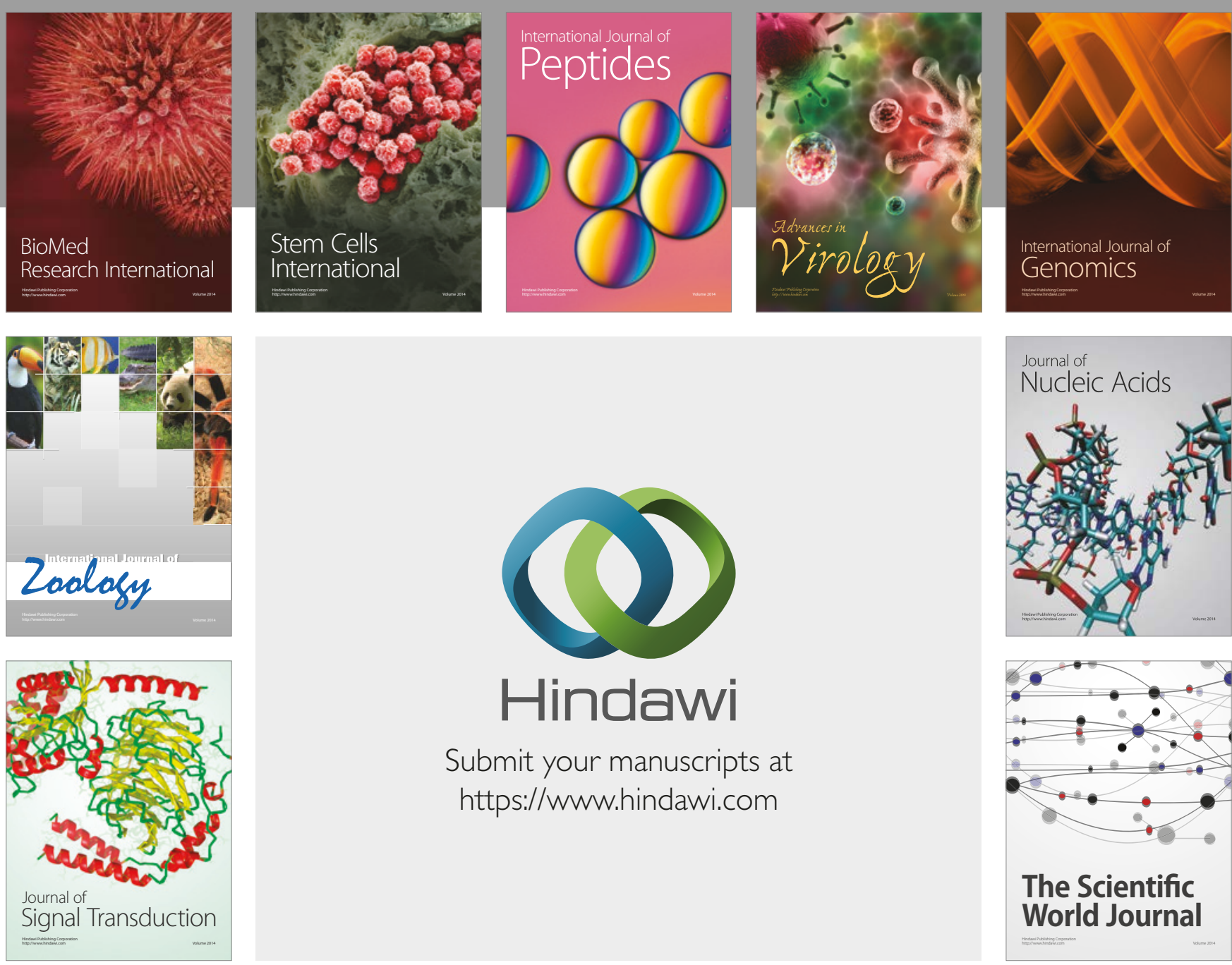

Submit your manuscripts at

https://www.hindawi.com
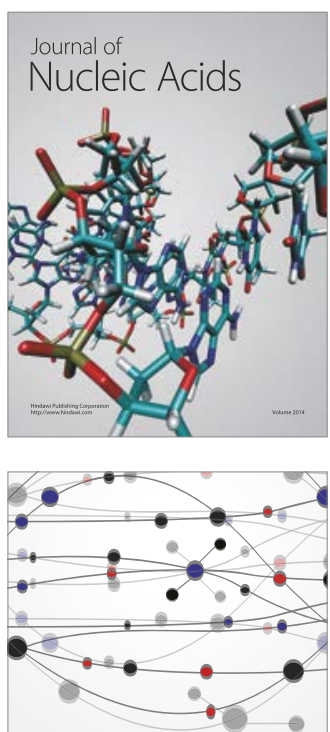

The Scientific World Journal

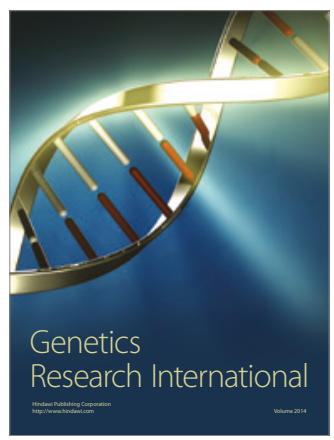

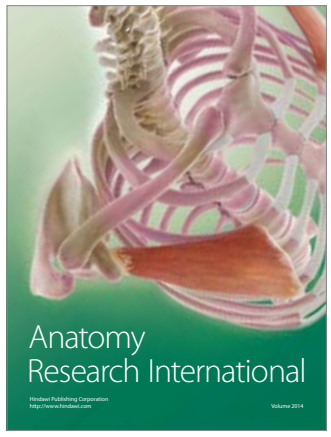

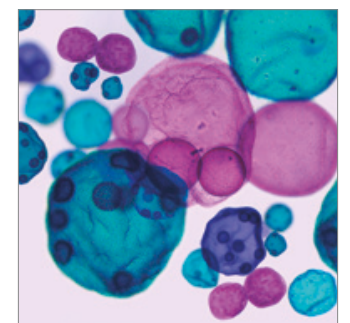

International Journal of Microbiology
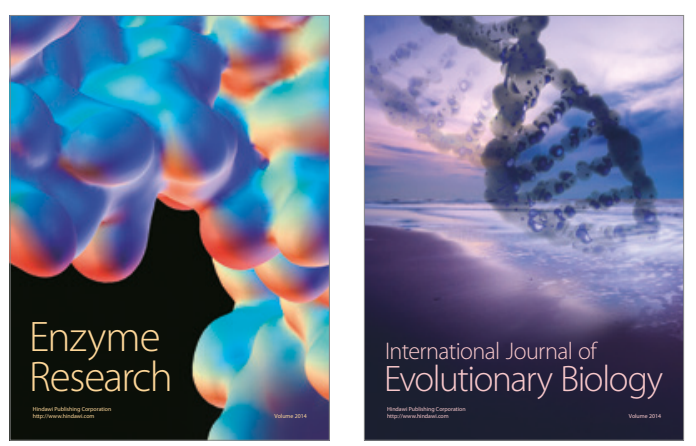
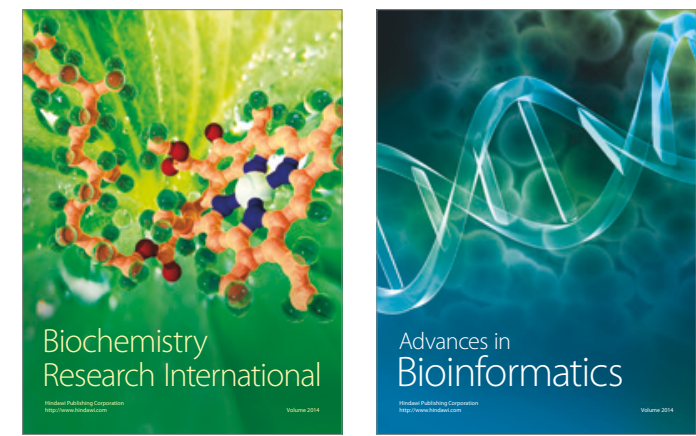

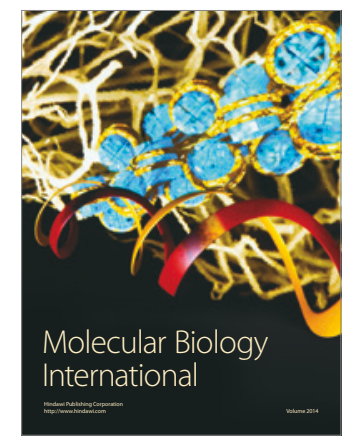

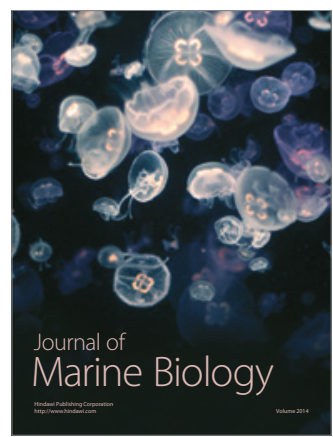

